\title{
ANALISIS PENGARUH DPK, NPL, DAN ROA TERHADAP PENYALURAN KREDIT BPR DI KABUPATEN KEDIRI PERIODE 2014-2018
}

\author{
Maria Eka Sihlestari \\ Henrycus Winarto \\ Mintarti Ariani
}

Fakultas Bisnis dan Ekonomika, Universitas Surabaya, Indonesia

Email: maria.eka29@gmail.com

\begin{abstract}
Essentially, the bank is financial institution which has the function to raise funds from the community in the form of deposits, and the channel it back to the community in the form of credit or other. Credits is the main activities performed by Bank Perkreditan Rakyat, because it will be makes a profit. However, the presenting credits will also provide a lot of risks that must be received or experienced by the BPR, because the risks that will be received or experienced are sourced to credit. Therefore, this researh is purpose to analys the effect of DPK, NPL, and ROA, on parcial althought simultan in contribute BPR credits. This researh conducted is quantitative approach use data panel regression method, and the data obtained are secondary data. According to the results of regression, the variables DPK and ROA have a significant influence on credit distribution. While, the NPL variable doesn't have a significant influence on credit distribution.
\end{abstract}

Kata-kata Kunci: BPR, Kredit, DPK, NPL, ROA

\section{PENDAHULUAN}

Indonesia merupakan negara yang memiliki potensi cukup besar untuk menjadi negara maju dalam perekonomiannya, hal ini didukung oleh jumlah sumberdaya manusia dan sumberdaya alam yang besar. Namun, pemerataan ekonomi belum sepenuhnya tercapai, karena masih banyak masyarakat yang memiliki akses terbatas terhadap sumberdaya ekonomi. Pada akhirnya, keterbatasan tersebut membuat masyarakat menengah ke bawah memiliki kehidupan ekonomi yang rendah (Hamidi, 2017).

Kehidupan ekonomi yang rendah tidak membuat masyarakat menengah ke bawah menjadi putus asa. Banyak ide atau cara untuk meningkatkan kondisi perekonomian, misal dengan cara memanfaatkan sumberdaya yang ada di Indonesia. Sumberdaya yang ada akan dimanfaatkan oleh masyarakat untuk membuka peluang usaha dan juga mengurangi tingkat pengangguran. Dalam dunia perbankan keberadaan BPR sangat penting khususnya sebagai lembaga keuangan yang bertujuan untuk melayani kebutuhan pelayanan jasa-jasa perbankan bagi masyarakat dengan ekonomi lemah dan usaha kecil di Indonesia. BPR ikut berkontribusi meningkatkan perekonomian masyarakat pada sektor ekonomi mikro dengan cara memberikan akses terhadap kebutuhan sumber daya finansial berupa kredit. Hal ini karena peran BPR sangat penting dalam memajukan ekonomi masyarakat di daerah-daerah setempat (Hamidi, 2017). 
Penyaluran kredit kepada masyarakat memiliki arti yang sangat penting, baik bagi masyarakat maupun bagi bank itu sendiri. Karena, masyarakat akan memperoleh dana untuk modal usahanya, dan bank akan memperoleh pendapatan bunga dari hasil pinjaman yang dilakukan oleh masyarakat tersebut. Sehingga, kegiatan ini dapat menggerakkan roda perekonomian suatu negara, terutama di Indonesia.

Lokasi BPR yang dekat dengan masyarakat, prosedur sederhana, mengutamakan pendekatan personal dan fleksibel dalam hal pola dan model pinjaman (kredit), membuat masyarakat atau nasabah menjadi lebih mudah dalam memahami dan mengerti mengenai prosedur atau tata cara jika suatu saat ingin mengajukan kredit di BPR. Jumlah BPR di wilayah Kabupaten Kediri, yaitu ada 18 BPR. Wilayah Kabupaten Kediri memiliki banyak komoditas unggulan, luas wilayahnya hanya 5\% dari luas keseluruhan Provinsi Jawa Timur. Namun, Kabupaten Kediri memiliki potensi bisnis yang cukup menjanjikan, sehingga secara perlahan perekonomian masyarakat setempat juga mulai ikut terangkat. Jumlah BPR yang ada di Kabupaten Kediri, yaitu ada 18 BPR. Penelitian hanya megambil sample 5 BPR yang ada di Kabupaten Kediri untuk dilakukan penelitian mengenai pengaruh DPK, NPL, dan ROA terhadap penyaluran kredit pada BPR. Sample tersebut dipilih berdasarkan BPR yang memiliki laporan keuangan yang dipublikasikan oleh OJK secara lengkap pada 2014-2018. BPR tersebut adalah: BPR Prima Dadi Arta, BPR Tanjung Tani, BPR Tulus Puji Rejeki, BPR Bank Daerah, dan juga BPR Agro Cipta Adiguna. Data penyaluran kredit terhadap 5 (lima) BPR di Kabupaten Kediri periode 2014-2018 tiap tahun mengalami perubahan yang fluktuatif. Pada 2014 tingkat penyaluran kredit pada 5 BPR di Kabupaten Kediri adalah 100.110.691 miliar rupiah, kemudian mengalami kenaikan sebesar 8.207.515 miliar rupiah di tahun 2015. Pada 2016 tingkat penyaluran kredit pada 5 BPR mengalami penurunan menjadi 106.275.239 miliar rupiah. Di tahun berikutnya, penyaluran kredit mulai meningkat kembali, yaitu sebesar 2.170.806 miliar rupiah pada 2017, dan 429.298 jutar upiah tahun 2018

BPR sangat membutuhkan Dana Pihak Ketiga dalam menjalankan operasinya,karena DPK merupakan dana berupa simpanan dari masyarakat. Selain itu, Non-Performing Loans juga memberikan pengaruh kepada kinerja BPR, karena semakin tinggi NPL, maka penyaluran kredit akan semakin berkurang. Bank Indonesia telah menentukan besaran NPL, yaitu sebesar 5\%. Tingkat profitabilitas atau Return on Assets juga selalu menjadi perhatian bank, karena merupakan cara bagaimana bank tersebut mampu mengoptimalkan aktiva yang dimiliki, sehingga mampu menghasilkan pendapatan (Arianti, dkk, 2016).

Undang-Undang Nomor 10 tahun 1998 tentang Perbankan (pasal 1 ayat 5) menjelaskan bahwa dana pihak ketiga atau simpanan adalah dana yang dipercayakan oleh masyarakat kepada bank berdasarkan perjanjian penyimpanan dana dalam bentuk giro, deposito, sertifikat deposito, tabungan, dan atau dalam bentuk lainnya yang dipersamakan dengan itu. Sumber dana yang diperoleh dari dana pihak ketiga akan memberikan dampak pada kemampuan dalam memenuhi skala dan volume transaksi yang pada akhirnya akan dapat meningkatkan laba. Sedangkan, menurut Pratama (2010), Dana Pihak Ketiga (DPK) berpengaruh positif dan signifikan terhadap kredit perbankan. Dengan demikian dapat diprediksi, bahwa DPK dapat memberikan pengaruh yang positif terhadap penyaluran kredit perbankan. Karena, apabila DPK naik, maka penyaluran kredit kepada masyarakat juga akan ikut naik.

Dalam melakukan pemberian kredit bank akan dihadapkan pada risiko kredit, yaitu nasabah tidak mampu membayar, sehingga menimbulkan kredit bermasalahyang disebut NonPerforming Loan (NPL). Non-Performing Loan (NPL), adalah rasio antara jumlah total kredit dengan kualitas kurang lancar, diragukan, dan macet terhadap total kredit (Peraturan Bank Indonesia Nomor 17/11/PBI/2015). Menurut Pratama (2010), rasio NPL menunjukan pengaruh yang negatif dan signifikan terhadap penyaluran kredit perbankan. Karena semakin tinggi rasio Non-Performing Loan (NPL), maka akan semakin besar risiki kredit yang akan

ditanggung oleh pihak bank. Sehingga, bank akan lebih berhati-hati dan lebih selektif lagi 
dalam menyalurkan kredit kepada masyarakat.

ROA adalah rasio yang digunakan untuk mengukur kemampuan suatu bank untuk menghasilkan laba dengan menggunakan total aset yang dipunyai oleh bank tersebut, setelah disesuaikan dengan biaya-biaya yang digunakan untuk mendanai aset tersebut. Menurut Yuwono (2012), rasio ROA menunjukan pengaruh yang positif dan tidak signifikan terhadap penyaluran kredit perbankan. Karena, semakin meningkat rasio ROA, maka akan memberikan penurunan terdahap likuiditas.

Banyak penelitian telah dilakukan untuk mengetahui pengaruh DPK, NPL dan ROA terhadap penyaluran kredit BPR. Penelitian yang dilakukan oleh Subegti (2010) mengenai determinasi penyaluran kredit pada Bank Umum di Indonesia, Subegti sebagai penulis menggunakan Dana Pihak Ketiga (DPK), Capital Adequancy Ratio (CAR), Non- Peforming Loan (NPL), BOPO, Return on Assets (ROA), penempatan dana SBI, dan market share sebagai variabel independenya. Sedangkan untuk variabel dependennya adalah jumlah kredit. Hasil dari penelitian ini menunjukan bahwa, rasio NPL, BOPO, DPK, dan market share memberikan pengaruh yang tidak signifikan tehadap penyaluran jumlah kredit perbankan. Sedangkan, untuk rasio CAR dan ROA menunjukan korelasi yang positif dan signifikan terhadap penyaluran jumlah kredit. ROA memiliki pengaruh yang positif dansignifikan, ini menunjukan profitabilitas bank yang mengalami peningkatan akan diikuti juga dengan peningkatan penyaluran kredit. Dan untuk SBI, menunjukan pengaruh yang negatif dan signifikan terhadap penyaluran jumlah kredit perbankan pada bank umum di Indonesia. Sedangkan NPL memberikan pengaruh yang negatif dan tidak signifikan.

Pratama (2009), penelitiannya mengenai analisis faktor-faktor yang mempengaruhi kebijakan penyaluran kredit perbankan, menggunakan DPK, CAR, NPL, dan suku bunga SBI sebagai variabel independennya, sedangkan untuk variabel dependennya adalah penyaluran kredit perbankan. Berdasarkan penelitian ini, diperoleh hasil bahwa DPK berpengaruh positif dan signifikan terhadap penyaluran kredit perbankan. Sedangkan, CAR dan juga NPL berpengaruh negatif dan signifikan terhadap penyaluran kredit perbankan. Sementara itu, suku bunga SBI memberikan pegaruh yang positif dan tidak signifikan terhadap peyaluran kredit perbankan. untuk meningkatkan penyaluran kredit, Bank Umum harus melakukanpenghimpunan dana secara optimal, mengoptimalkan kegunaan sumber daya financial (modal) yang dimiliki, dan juga memiliki manajemen perkreditan yang baik agar yang baik, agar NPL tetap berada dalam tingkat yang rendah dan dalam batas yang disyaratkan oleh Bank Indonesia.

Yuwono (2012) penelitiaannya mengenai analisis pengaruh DPK, LDR, CAR,NPL, ROA, dan SBI terhadap jumlah penyaluran kredit bank yang terdaftar di BEI tahun 2007-2010. Variabel independen yang digunakan adalah DPK, LDR, CAR, NPL, ROA, dan SBI, sedangkan varibel dependennya adalah jumlah kredit yang disalurkan. Teknik analisis yang digunakan adalah analisis regresi linier berganda. Dari hasil pengujian menunjukan, bahwa DPK dan LDR berpengaruh positif dan signifikan terhadap penyaluran kredit. Sementara itu, CAR, ROA, SBI memberikan pengaruh positif dan tidak signifikan, dan NPL memberikan pengaruh yang negatif dan signifikan terhadap penyaluran kredit.

\section{METODE PENELITIAN}

Jenis penelitian yang digunakan dalam penelitian ini adalah menggunakan penelitian regresi data Panel (Pooled Data). Data Panel (PooledData) merupakan teknik regresi yang menggabungkan antara data runtut waktu (time series) dengan data silang (cross section). Penelitian jenis regresi linier berganda dapat mengunakan metode OLS (Ordinary Least Square) dengan fungsi Penyaluran Kredit BPR di Kabupaten Kediri = f (DPK, NPL, ROA), sehingga persamaan regresi: 


\section{Kredit $_{i t}=\alpha+\beta_{1} D_{P K}+\beta_{2} N_{12} L_{i t-1}+\beta_{3} R_{0} A_{i t}+\varepsilon_{i t}$}

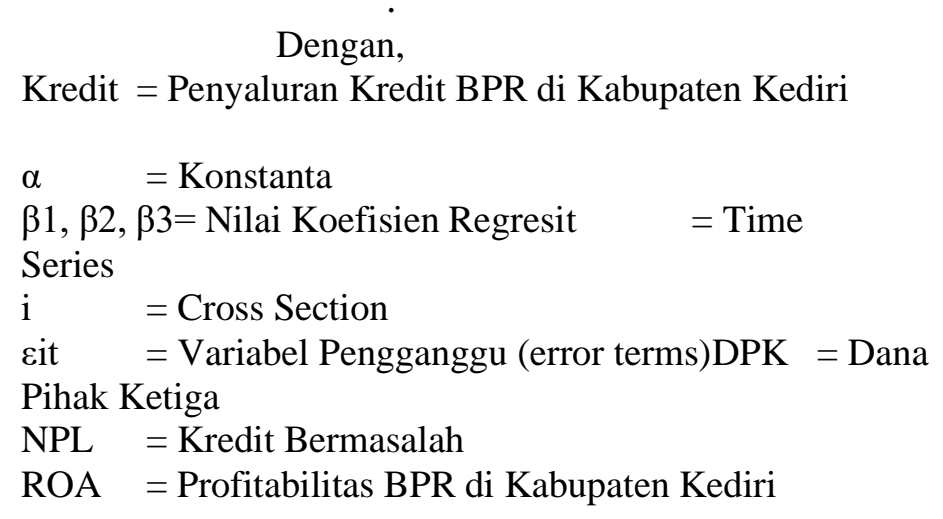

Estimasi yang dilakukan terhadap data panel adalah menggunakan regresi data panel. Regresi yang dilakukan menggunakan tiga macam metode estimasi, yaitu Common Effect Model, Fixed Effect Model, dan Random EffectModel. Untuk memilih model mana yang paling efisien digunakan, makaharus dilakukan dengan menggunakan beberapa uji, seperti uji Chow-test dan uji Hausman-test.

\section{HASIL DAN PEMBAHASAN}

Hasil uji Chow-test menyatakan bahwa nilai probabilitas chi-square lebih kecil dari $5 \%$. Hasil tersebut menandakan terjadinya penolakan $\mathrm{H} 0$, danpenerimaan $\mathrm{H} 1$. Hal ini berarti bahwa model fixed effect lebih baik danefisien daripada model common effect.

Hasil uji Hausman-test diketahui bahwa model yang terbaik dan efisen adalah model fixed effect. Hasil tersebut disimpulkan berdasarkan nilai probabilitas chi-square yang bernilai lebih kecil dari 5\%. Sehingga, hasiltersebut menunjukan H0 ditolak, sedangkan H1 diterima.

Hasil regresi menunjukan variabel $\mathrm{X}_{1}(\mathrm{DPK})$ memiliki koefisien 0,571258 , nilai standard error sebesar 0,055942, dan nilai t-statistik 10,21165 dengan tingkat signifikan 0,0000, sehingga dapat diartikan bahwa telah terjadipenolakan $\mathrm{H}_{0}$ untuk variabel $\mathrm{X}_{1}(\mathrm{DPK})$. Dengan demikian $\mathrm{H}_{1}$ yang menyatakan bahwa DPK berpengaruh terhadap penyaluran kredit diterima. Pengaruh DPK terhadap penyaluran kredit sebesar 0,571258. Artinya, jika DPK naik 0,571258 satuan, maka penyaluran kredit akan naik sebesar 1satuan, dengan asumsi faktorlain dianggap tetap.

Variabel $\mathrm{X}_{2}$ (NPL) memiliki nilai koefisien sebesar 11607301. Nilai koefisien tersebut menandakan bahwa, bila NPL naik maka penyaluran kredit akan turun. Pengaruh NPL terhadap penyaluran kredit adalah tidak signifikan dengan tingkat signifikan di atas $5 \%$. Artinya, $\mathrm{H}_{2}$ yang menyatakan bahwa NPL berpengaruh terhadap penyaluran kredit BPR di Kabupaten Kediri ditolak. Jika NPL turun sebesar 11607301 satuan, maka penyaluran kredit akan naik sebesar 1 satuan, dengan asumsi faktor lain dianggap tetap.

Variabel $\mathrm{X}_{3}$ (ROA) memiliki nilai koefisien sebesar 1,89000000 , nilai standard error sebesar 67352310, dan juga memiliki nilai probabilitas 0,0061. Jika nilai ROA naik sebesar 1,89000000 satuan, maka penyaluran kredit juga akan naik 1 satuan, dengan asumsi faktor lain dianggap tetap. Tingkat signifikansi $\mathrm{X}_{3}$ (ROA) yang signifikan dibawah 5\% menunjukan bahwa ROA berpengaruh terhadap penyaluran kredit, dan menerima $\mathrm{H}_{3}$. Asumsinya, jumlah penyaluran kredit pada BPR di Kabupaten Kediri akan meningkat, apabila kuantitas ROA juga meningkat. Karena peningkatan ROA akan membawa pengaruh yang positif bagi BPR dalam menyalurkan kredit kepada masyarakat.

Uji F memiliki nilai probabilitas sebesar 0,000000. Nilai tersebut menunjukan bahwa variabel independen secara simultan mempengaruhi variabel dependen.

Nilai R-Square adalah 0,987777. Hasil tersebut dapat diartikan bahwa variabel independen 
yang diteliti dalam model dapat menjelaskan variabel dependen sebesar 98\%, sedangkan sisanya dijelaskan oleh variabel lain yang tidak diteliti pada penelitian ini.

Salah satu sumber dana yang dimiliki oleh BPR di Kabupaten Kediri adalah DPK. BPR dapat menggunakan DPK untuk memenuhi kebutuhan penyaluran kredit. Hasil menunjukan bahwa DPK berpengaruh positifterhadap penyaluran kredit, dimana DPK yang semakin tinggi akan membuat BPR semakin memiliki banyak dana untuk memenuhi kebutuhan penyaluran kredit kepada masyarakat. Hasil ini sejalan dengan penelitian Pratama (2010) dan Yuwono (2012), yang menyatakan bahwa DPK berpengaruh positif dan signifikan terhadap penyaluran kredit BPR di Kabupaten Kediri.

NPL adalah akibat dari peningkatan resiko kredit yang dihadapi oleh BPR di Kabupaten Kediri, karena BPR tersebut telah melakukan ekspansi terhadap penyaluran kredit. Semakin tinggi BPR dalam menyalurkan kredit kepada masyarakat tanpa diimbangi dengan mitigasi resiko, maka NPL akan meningkat. Pada penelitian ini, hasil pengaruh dari NPL terhadap penyaluran kredit pada BPR di Kabupaten Kediri telah gagal menunjukan tingkat signifikan, sehingga seberapa besar nilai NPL tidak akan mempengaruhi penyaluran kredit pada BPR di Kabupaten Kediri, jadi fenomena hasil NPL yang positif dapat diabaikan. Oleh karena itu, dapat diambil kesimpulan bahwa NPL tidak berpengaruh terhadap penyaluran kredit pada BPR di Kabupaten Kediri. Hal ini sejalan dengan hasil penelitian Haryanto dan Widyarti (2017), NPL menunjukan hasil yang positif dan tidak signifikan. Namun, kegiatan penyaluran kredit akan tetap disalurkan oleh BPR, apabila NPL masih berada pada batas yang aman.

ROA adalah besaran pendapatan dibandingkan dengan jumlah aset yang dimiliki. Jika pendapatan semakin tinggi, maka bisnis yang dijalankan oleh perusahaan sedang dalam peforma yang bagus. Sehingga, BPR dapat lebih berekspansi dalam melakukan penyaluran kredit di masyarakat. Hal ini sejalan dengan pemikiran Subegti (2010), dimana ROA menunjukan pengaruhyang positif dan signifikan terhadap penyaluran kredit di Kabupaten Kediri. DPK pada BPR di Kabupaten Kediri memiliki pengaruh yang positif dan signifikan terhadap penyaluran kredit di Kabupaten Kediri pada periode 2014-2018. Dimana, DPK yang semakin tinggi akan membuat BPR di Kabupaten Kediri semakin memiliki banyak dana untuk memenuhi kebutuhan penyalurankredit kepada masyarakat.

\section{KESIMPULAN}

NPL pada BPR di Kabupaten Kediri memiliki pengaruh yang positif dan tidak signifikan terhadap penyaluran kredit di Kabupaten Kediri pada periode 2014-2018. Pada hal ini, fenomena hasil positif dapat diabaikan, karena nilai NPL telah gagal menunjukan tingkat signifikan, sehingga seberapa besar nilai NPL tidak akan mempengaruhi penyaluran kredit pada BPR di Kabupaten Kediri. Namun, penyaluran kredit akan tetap disalurkan apabila nilai NPL masih dalam batas yang aman. Karena, semakin tinggi BPR dalam melakukan penyaluran kredit tanpa diimbangi dengan mitigasi resiko, maka akan membuat NPL meningkat.

ROA pada BPR di Kabupaten Kediri memiliki pengaruh yang positif dan signifikan terhadap penyaluran kredit BPR di Kabupaten Kediri pada periode 2014-2018. Karena, apabila pendapatan semakin tinggi, maka bisnis yang dijalankan oleh perusahaan sedang dalam performa yang bagus.

DPK, NPL, dan ROA pada BPR di Kabupaten Kediri secara simultan memiliki pengaruh yang signifikan terhadap penyaluran kredit diKabupaten Kediri pada periode 20142018.

\section{DAFTAR PUSTAKA}

Arianti, Dwinur., Andini Rita, dan Arifati Rina. 2016. Pengaruh BOPO, NIM, NPL, dan CAR terhadap Jumlah Penyaluran Kredit pada Perusahaan Perbankan yang Go Public di Bursa 
Efek Indonesiaperiode tahun 2010-2014. Journal of Accounting, Volume 2, Nomor 2.

Hamidi, Masyhuri. 2017. Studi Komparasi Kinerja Bank Perkreditan Rakyat (BPR) Syariah dan Konvensional di Sumatera Barat. Jurnal Iqtishadia, Volume 10, Nomor 1, Halaman 44-70.

Haryanto, S.B., dan Widyarti, E.T. (2017). Analisis Pengaruh NIM, NPL, BOPO, BI Rate, dan CR terhadap Penyaluran Kredit BankUmum Go Publik periode 2012-2016. Diponegoro Journal of Management, Volume 6, Nomor 4, Halaman 1-11.

Pratama, Billy Arma. 2010. Analisis Faktor-Faktor yang Mempengaruhi Kebijakan Penyaluran Kredit Perbankan (Studi pada Bank Umum di Indonesia Periode Tahun 2005-2009). Thesis. Semarang: Program Studi Manajemen Program Pasca Sarjana Universitas Diponegoro. 